\title{
Effect of Water Absorption on Dielectric Constant of TMD Cured of Carbonaceous Filled Epoxy Composites
}

\author{
Muhammad Helmi Abdul Kudus, ${ }^{1}$ Hazizan Md. Akil, ${ }^{1,2 *}$ Muhammad Razlan Zakaria ${ }^{1}$ \\ and Muhammad Bisyrul Hafi Othman ${ }^{1}$ \\ ${ }^{1}$ School of Materials and Minerals Resources Engineering, Universiti Sains Malaysia, \\ Engineering Campus, 14300 Nibong Tebal, Pulau Pinang, Malaysia \\ ${ }^{2}$ Cluster for Polymer Composite (CPC), Science and Engineering Research Center, \\ Universiti Sains Malaysia, Engineering Campus, 14300 Nibong Tebal, \\ Pulau Pinang, Malaysia
}

"Corresponding email: hazizan@usm.my

Published online: 15 February 2019

To cite this article: Abdul Kudus, M. H. et al. (2019). Effect of water absorption on dielectric constant of TMD cured of carbonaceous filled epoxy composites. J. Phys. Sci., 30(Supp. 1), 101-107, https://doi.org/10.21315/jps2019.30.s1.6

To link to this article: https://doi.org/10.21315/jps2019.30.s1.6

\begin{abstract}
Carbon nanotubes (CNT) and graphene nanoparticles (GNP) have been used as carbonaceous filler in epoxy composites based on the diglycidyl ether of bisphenol A (DGEBA) cured with tetra methyl diamine (TMD). Both CNT/epoxy and GNP/epoxy nanocomposites were subjected to ageing at 0\%, 30\%, 50\%, 70\% and $100 \%$ of relative humidity at room temperature for three weeks. Both composites show increasing water absorption percentage at higher relative humidity. Moreover, the GNP/epoxy nanocomposites showed a higher water absorption compared to CNT/epoxy nanocomposites. The dielectric constant increment of both nanocomposites is parallel to the water absorption properties. It is concluded that water absorption leads both to increase the dielectric constant of the epoxy resin.
\end{abstract}

Keywords: Water absorption, epoxy nanocomposites, carbon nanotube, graphene, graphene nanoparticles

\section{INTRODUCTION}

Since their commercial introduction, epoxies have become an essential part of insulation materials. The versatility, stability under extreme conditions, and ease of use has significantly improved the electrical devices that relies on their insulating abilities. ${ }^{1-3}$ From the smallest computer chip to the largest motors and 
generators, epoxies serve their purpose from time to time. The close observation of the processes and modifications have been used to follow the rapid development in both devices and materials to ensure solutions to the predictable problems. In electronic devices industry, epoxy composites were used due to their insulation abilities as well as their optical, mechanical and chemical properties. ${ }^{4,5}$ The insulation abilities of epoxy rely on its low dielectric constant. Owing its tailorable nature, the dielectric constant of epoxy could be modified in several ways, such as modification of chemical structure and incorporating the dielectric fillers. ${ }^{6,7}$ The easier way to modify the dielectric constant is by incorporating the dielectric fillers such as metal, ceramic and carbonaceous particles. ${ }^{8-13}$

Among these three types of dielectric fillers, carbonaceous filler seems more effective to modify the dielectric constant of epoxy composites due to their compatibility with the epoxy matrix. ${ }^{14}$ Carbon nanotube (CNT) and graphene nanoparticles (GNP) are the most popular carbonaceous fillers in polymer composites technology nowadays. Epoxy composites filled with CNT and GNP usually increase the dielectric constant of epoxy composites. However, the dielectric constant of the composites would be affected by the humidity of the environment depending on the water absorption behavior of the composites. Water absorption properties of epoxy nanocomposites is important especially in electronic application because it has direct effect to the dielectric properties of the material and eventually affect the impedance of electronic components. In this paper, we aim to investigate the water absorption behaviors of the epoxy/CNT and epoxy/GNP nanocomposites and their effect on dielectric constant of the composites.

\section{EXPERIMENTAL}

\subsection{Materials}

Diglycidyl ether of bisphenol A or epoxy resin DER 331 (DGEBA) was purchased from Dow Chemical (Malaysia) Sdn. Bhd. CNT and GNP were obtained from Skyspring Nanomaterials Inc. and were used as composite fillers. The CNT is multiwalled-CNT. Trimethylhexaethylene diamine (TMD) which acts as a curing agent was obtained from Sigma-Aldrich (M) Sdn. Bhd. Silica gel, magnesium chloride $\left(\mathrm{MgCl}_{2}\right)$, magnesium nitrate $\left(\mathrm{MgNO}_{3}\right)$, sodium chloride $(\mathrm{NaCl})$ and deionised water were used for relative humidity environment. All materials were used as received. 


\subsection{Epoxy Nanocomposite Preparation}

The ratio of DGEBA, TMD and GNP used in this experiment is $10: 6: 1$ by weight percentage. The GNP was added into DGEBA and stirred under $80 \mathrm{rpm}$ for $5 \mathrm{~min}$ and sonicate using high frequency sonicator for $2 \mathrm{~min}$. The mixture was then put in a vacuum for $5 \mathrm{~min}$ to eliminate air bubbles. Then TMD was added into the mixture and stirred under $80 \mathrm{rpm}$ for another $5 \mathrm{~min}$. The final mixture was put into the vacuum to eliminate trapped air bubbles. The mixture was put into the mold and cured at room temperature for $24 \mathrm{~h}$. The same procedure was repeated by substituted GNP with CNT. Neat epoxy with 10:6 ratio of DGEBA and TMD was also prepared as control subject.

\subsection{Water Absorption Test}

The water absorption test was conducted under five different relative humidity (RH) conditions. The equilibrium RH environment was prepared using different saturated salt solution according to Arnold Wexler et al. ${ }^{15}$ Silica gel represents approximately $\mathrm{RH} 0 \%, \mathrm{MgCl}_{2}$ (RH 30\%), $\mathrm{MgNO}_{3}$ (RH 50\%), $\mathrm{NaCl}(\mathrm{RH} 70 \%$ ) and deionised water (RH 100\%). The initial weight of epoxy/GNP and epoxy/ CNT nanocomposites samples were recorded before the test. The samples soaked into the solutions for three weeks. The weight after three weeks was recorded. The water absorption was calculated using Equation 1:

$$
\text { Water absorption }=[(\mathrm{A}-\mathrm{B}) / \mathrm{B}] \times 100 \%
$$

\subsection{Dielectric Constant Test}

The dielectric constant test was conducted using Agilent RF Analyser. Each sample (neat epoxy, GNP/epoxy and CNT epoxy nanocomposites) with all RH aged condition were tested. The RF Analyser give the dielectric constant and loss tangent data at $1 \mathrm{GHz}$ for each sample.

\section{RESULTS AND DISCUSSION}

The water absorption of epoxy and epoxy composites increases with the increasing relative humidity. It was due to the nature of diamine cured epoxy having a lot of hydroxyl (-OH) functional groups in the crosslink networks. ${ }^{16}$ The - $\mathrm{OH}$ groups and water molecules could form strong hydrogen bonds. ${ }^{17}$ The -OH groups tend to attract water molecules from the environment and depicted as water absorption properties. Figure 1 shows the difference water absorption percentage among neat epoxy, epoxy/GNP and epoxy/CNT. Both epoxy/GNP 
and epoxy/CNT show slightly higher water absorption percentage compare to the neat epoxy. Both epoxy/GNP and epoxy/CNT were incorporated with GNP and CNT fillers respectively. CNT always tend to agglomerate in epoxy resins regarding to its wire-like shape and van der Waals force. ${ }^{18}$ The agglomeration of CNT would create some non-wettability clusters which further attracted the water molecules from the environment. Moreover, the agglomeration of CNT would form "capillaries" which resembles to activated carbon. Unlike "smooth" surface of CNT, GNP are flake-shape nanoparticles which possesses a lot of -OH and $-\mathrm{COOH}$ functional groups on the surface. These functional groups would make the epoxy/GNP composite absorbed more water compared to epoxy/CNT. Figure 2 shows the schematic structure of CNT and GNP.

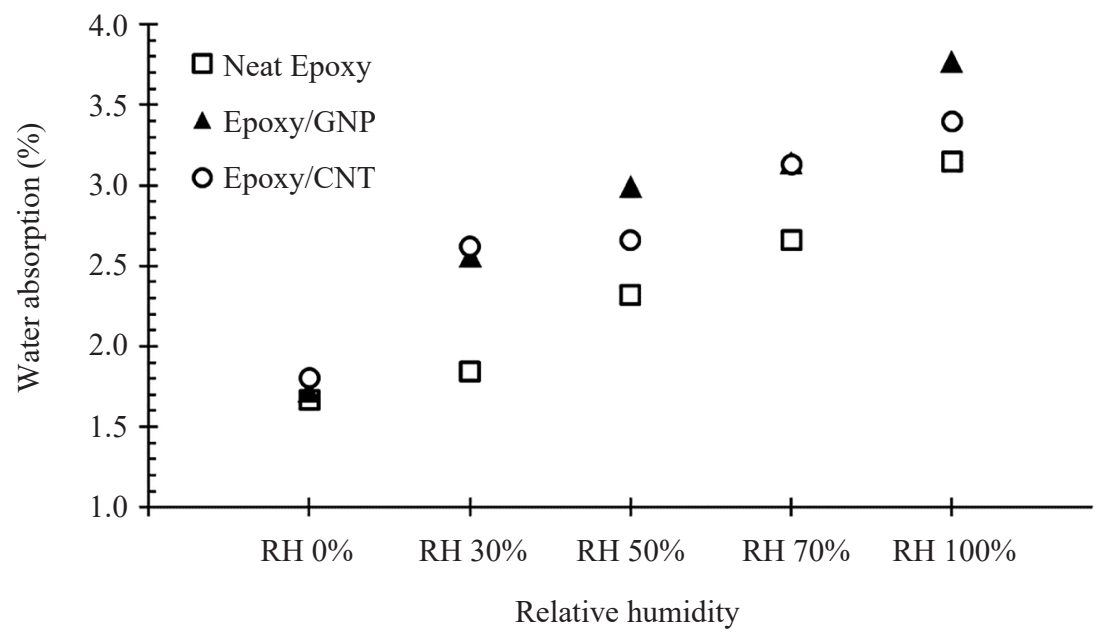

Figure 1: Comparison of water absorption percentage among neat epoxy, epoxy/GNP and epoxy/CNY nanocomposites with exposure in different relative humidity.

(a)

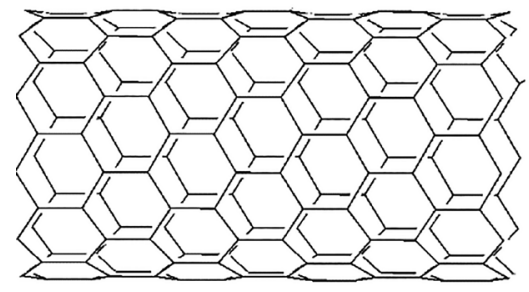

Carbon Nanotube (CNT) (b)

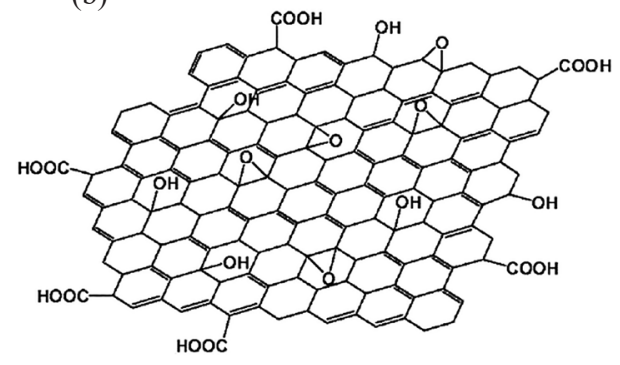

Graphene Nanoparticle (GNP)

Figure 2: Schematic structure of (a) CNT and (b) graphene. 
Dielectric constant of neat epoxy and epoxy composites increased with the increasing of relative humidity which directly related to the water absorption. The higher water content in epoxy and epoxy composites would increase the dielectric constant. Figure 3 shows the comparison of dielectric constant among neat epoxy, epoxy/GNP and epoxy/CNT. At lower relative humidity, epoxy/ GNP and epoxy/CNT were having about the same dielectric constant due to same graphitic structure of both GNP and CNT which increased the dielectric constant of the composites. The agglomeration of both GNP and CNT would give closer characteristic of filler reinforcement. The increment of dielectric constant from neat epoxy to the carbonaceous filled epoxy is slightly influenced by the filler type. However, at higher relative humidity, epoxy/GNP showed higher dielectric constant than epoxy/CNT. This result is due to the higher water absorption of epoxy/GNP dominated the factor of dielectric constant increment. Moreover, the GNP contains more oxygen moieties responsible for better interaction with the epoxy matrix. ${ }^{19}$

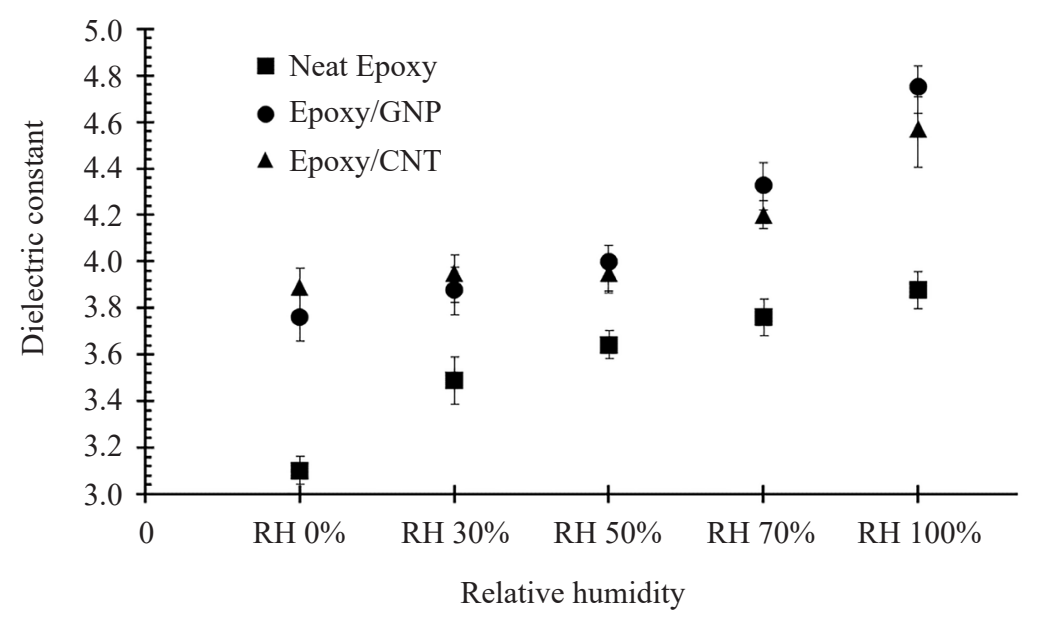

Figure 3: Comparison of dielectric constant at $1 \mathrm{GHz}$ among neat epoxy, epoxy/GNP and epoxy/CNT nanocomposites with exposure in different relative humidity.

\section{CONCLUSION}

Epoxy/GNP and epoxy/CNT composites show increasing water absorption percentage at higher relative humidity. Moreover, the epoxy/GNP nanocomposites showed a higher water absorption compared to epoxy/CNT nanocomposites. The dielectric constant increment of both nanocomposites is parallel to the water absorption properties. It is concluded that water absorption dominates the increase of the dielectric constant of epoxy composites. 


\section{ACKNOWLEDGEMENTS}

The authors wish to acknowledge Universiti Sains Malaysia (USM) for sponsoring this project under grant RUI (1001/PBAHAN/8014047) and School of Materials and Mineral Resources Engineering, Engineering Campus, USM for technical support.

\section{REFERENCES}

1. Dutta, S. S. (2008). Water absorption and dielectric properties of epoxy insulation. MSc. diss., Norwegian University of Science and Technology.

2. Vaishampayan, D. (2009). Dielectric spectroscopy of bisphenol a epoxy resin aged in wet and dry conditions. MSc. diss., Norwegian University of Science and Technology.

3. Zulfli, N. H. M. \& Shyang, C. W. (2010). Flexural and morphological properties of epoxy/glass fibre/silane-treated organo-montmorillonite composites. J. Phys. Sci., 21(2), 41-50.

4. Feldman, D. \& Barbalata, A. (1996). Synthetic polymers: Technology, properties, applications. London: Springer Science \& Business Media.

5. Chin, L.W., Hung, H. L. \& Shyang, C. W. (2010). Thermo-mechanical and light transmittance of silica diffusant filled epoxy composites. J. Phys. Sci., 21(1), 93-107.

6. Lee, J. et al. (2004). Study of new fluorine-containing epoxy resin for low dielectric constant. Surf. Coat. Technol., 180, 650-654, https://doi.org/10.1016/j. surfcoat.2003.10.111.

7. Hsuan Lin, C. et al. (2003). Low dielectric thermoset. I. Synthesis and properties of novel 2, 6-dimethyl phenol-dicyclopentadiene epoxy. J. Appl. Polym. Sci., 88(11), 2607-2613, https://doi.org/10.1002/app.11874.

8. Lu, J. et al. (2006). Synthesis and dielectric properties of novel high-K polymer composites containing in-situ formed silver nanoparticles for embedded capacitor applications. J. Mater. Chem., 16(16), 1543-1548, https://doi.org/10.1039/ b514182f.

9. Qi, L. et al. (2005). High-dielectric-constant silver-epoxy composites as embedded dielectrics. Adv. Mater., 17(14), 1777-1781, https://doi.org/10.1002/ adma.200401816.

10. Kuo, D.-H. et al. (2004). Dielectric properties of three ceramic/epoxy composites. Mater. Chem. Phys., 85(1), 201-206, https://doi.org/10.1016/j. matchemphys.2004.01.003.

11. Yung, K. et al. (2009). Preparation and properties of hollow glass microspherefilled epoxy-matrix composites. Compos. Sci. Technol., 69(2), 260-264, https://doi.org/10.1016/j.compscitech.2008.10.014. 
12. Sandler, J. et al. (2003). Ultra-low electrical percolation threshold in carbonnanotube-epoxy composites. Polym., 44(19), 5893-5899, https://oi.org/10.1016/ S0032-3861(03)00539-1.

13. Rao, Y. et al. (2002). Novel polymer-ceramic nanocomposite based on high dielectric constant epoxy formula for embedded capacitor application. J. Appl. Polym. Sci., 83(5), 1084-1090, https://doi.org/10.1002/app.10082.

14. Yang, C., Lin, Y. \& Nan, C. (2009). Modified carbon nanotube composites with high dielectric constant, low dielectric loss and large energy density. Carbon, 47(4), 1096-1101, https://doi.org/10.1016/j.carbon.2008.12.037.

15. Wexler, A. \& Hasegawa, S. (1954). Relative humidity-temperature relationships of some saturated salt solutions in the temperature range $0^{\circ} \mathrm{C}$ to $50^{\circ} \mathrm{C}$. J. Res. Nat. Bur. Stand., 53(1), 19-26, https://doi.org/10.6028/jres.053.003.

16. Othman, M. B. H. et al. (2016). The incorporation of hydroxyl terminated polydimethylsiloxane into dgeba epoxy resins via condensation of hydroxyl groups: Preliminary approach. Wal. J. Sci. Technol., 13(11).

17. Ding, Y. et al. (2001). Contributions of the side groups to the characteristics of water absorption in cured epoxy resins. Macromol. Chem. Phys., 202(13), 2681-2685, https://doi.org/10.1002/1521-3935(20010901)202:13\%3C2681::AIDMACP2681\%3E3.0.CO;2-E.

18. Mo, C. B. et al. (2005). Fabrication of carbon nanotube reinforced alumina matrix nanocomposite by sol-gel process. Mater. Sci. Eng. A, 395(1), 124-128, https://doi.org/10.1016/j.msea.2004.12.031.

19. Yue, L. et al. (2014). Epoxy composites with carbon nanotubes and graphene nanoplatelets: Dispersion and synergy effects. Carbon, 78, 268-278, https://doi. org/10.1016/j.carbon.2014.07.003. 